Provided for non-commercial research and education use. Not for reproduction, distribution or commercial use.

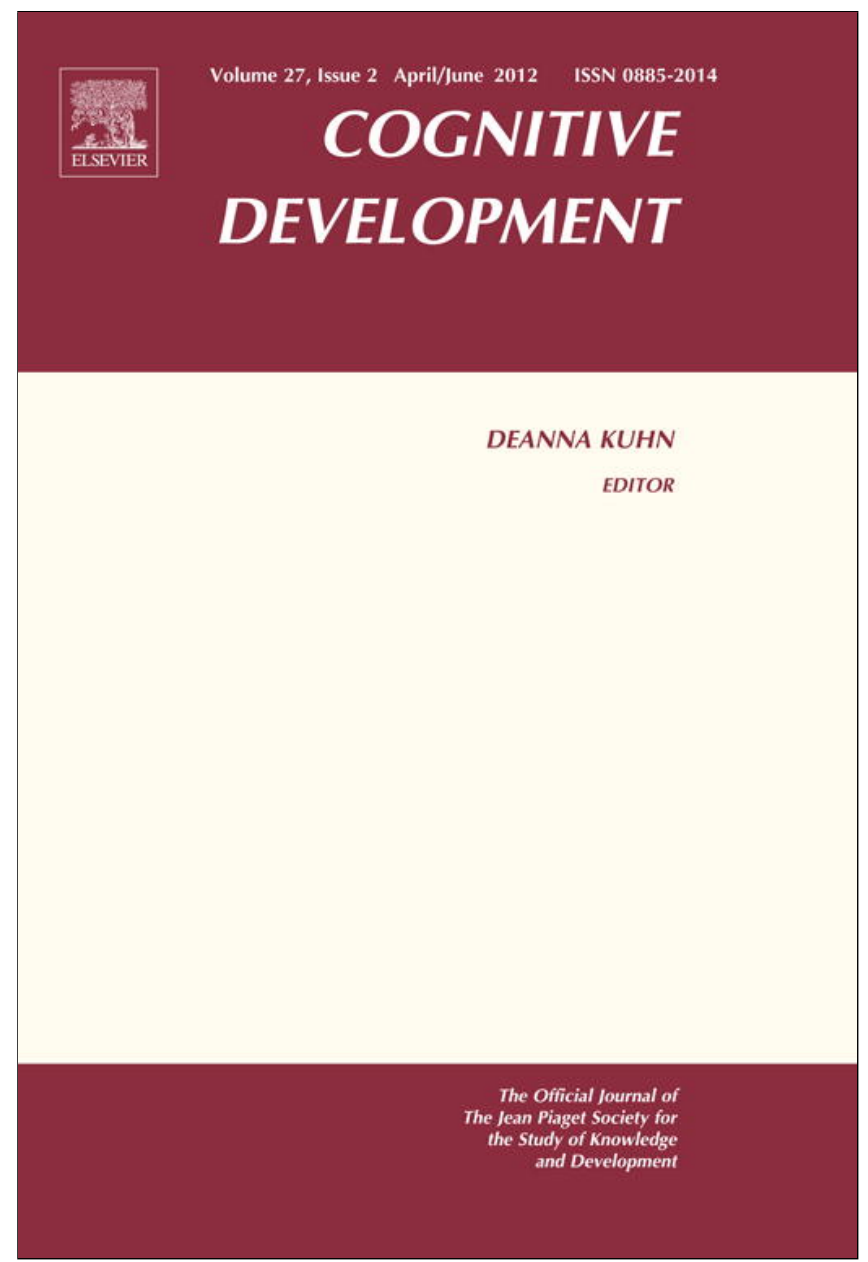

This article appeared in a journal published by Elsevier. The attached copy is furnished to the author for internal non-commercial research and education use, including for instruction at the authors institution and sharing with colleagues.

Other uses, including reproduction and distribution, or selling or licensing copies, or posting to personal, institutional or third party websites are prohibited.

In most cases authors are permitted to post their version of the article (e.g. in Word or Tex form) to their personal website or institutional repository. Authors requiring further information regarding Elsevier's archiving and manuscript policies are encouraged to visit:

http://www.elsevier.com/copyright 


\title{
How do use and comprehension of mental-state language relate to theory of mind in middle childhood?
}

\author{
Ilaria Grazzani*, Veronica Ornaghi \\ Università degli Studi di Milano-Bicocca, Department of Human Sciences R. Massa, Milan, Italy
}

\section{A R T I C L E I N F O}

\section{Introduction}

This study is a contribution to the well-established line of enquiry on the relationship between development of theory of mind (ToM) - or the capacity to recognize the internal states of self and others such as desires, beliefs, emotions and intentions - and linguistic ability, in terms of competence in specific types of lexicon.

\footnotetext{
* Corresponding author.

E-mail address: ilaria.grazzani@unimib.it (I. Grazzani).
} 
Data from previous studies on theory-of-mind development in children suggest that language plays a key role in acquiring an understanding of mental states (Astington, 2001; Harris, de Rosnay, \& Pons, 2005; Hughes, 2011; Hughes, Marks, Ensor, \& Lecce, 2010; Lohman \& Tomasello, 2003; Milligan, Astington, \& Dack, 2007; Ruffman, Slade, Rowlandson, Rumsey, \& Garnham, 2003; Slade \& Ruffman, 2005). It is through language that children participate in social interaction, conversational exchanges, pretend play, story-telling and other activities fostering their ability to link manifest actions and behaviors with mental states that are inaccessible to direct observation (Nelson, 2005).

An aspect of the relationship between language and ToM which has received much attention to date is lexical semantic competence. Many studies have shown that understanding of the mind and ability to pass false-belief tasks require knowledge of the psychological lexicon (Moore, Bryant, \& Furrow, 1989; Olson, 1988), that is the particular terms used to describe the mental states or internal worlds of self and others. This lexicon has also been referred to as language of mind or "metacognitive language" (Astington \& Pelletier, 1996) as it provides labels for mental states such as thinking, knowing, believing, and desiring. Ability to use this vocabulary is considered to be a key indicator of early ToM competencies, and a precursor of later metarepresentational ability (Bartsch \& Wellman, 1995). The psychological lexicon progressively extends to describing internal states of perception, volition, emotion, cognition and moral judgment; thus, observation of children's acquisition of these terms is an excellent tool for tracking their mental development. Past research has shown that between the ages of 2 and 4 children initially use psychological terms as a "conversational device" and later as a means of referring to mental states (Astington \& Peskin, 2004; Jenkins, Turrell, Kogushi, Lollis, \& Ross, 2003).

The word categories making up the mental-state language differ from one another both in complexity and in the order they are acquired by the developing child (Bretherton \& Beeghly, 1982). A number of longitudinal studies (Brown \& Dunn, 1991; Hughes \& Dunn, 1998) have indicated that the child first uses psychological terms to refer to itself («I want», «I like», «I know») and later to refer to the mental states of others ("You think», «He wants»). At around 2 years of age, children begin to make spontaneous conversational use of mental-state language relating to volition (for example, want, desire, hope, prefer) in reference to their own desires and the desires of others, and to perception (for example, see, hear, feel) in reference to the external world. At this age too, they make their first use of the lexicon of emotion, both positive (for example, happy) and negative (for example, afraid, angry). Initially they acquire the language of basic emotions (anger, fear, sadness and happiness) and subsequently that of complex and social emotions. At around 3 years of age, they start to use psychological terms relating to cognition to speak about thoughts, beliefs and imagination (for example, know, think, imagine, guess, believe, understand).

The link between use of mental state language and theory-of-mind development has been the focus of numerous studies with preschoolers. One of the aspects investigated is the correlation between maternal mental language and ToM development (Dunn, Brown, \& Beardsall, 1991; Ruffman, Slade \& Crowe, 2002). Longitudinal and cross-sectional studies have shown that the more a mother uses mental-state terms when speaking to her child, the better the child's understanding of false belief (Brown \& Dunn, 1991; Symons, Fossum, \& Collins, 2006) and of emotion (Taumoepeau \& Ruffman, 2008; Wang, Doan, \& Song, 2010) and the more frequently the child itself makes use of psychological lexicon (Howard, Mayeux, \& Naigles, 2008; Scholnick \& Hall, 1991). Other research with preschool children has indicated an association between the frequency with which they use mental-state terms during spontaneous conversation and their scores on false-belief ToM tasks (Brown, Donelan-McCall, \& Dunn, 1996; Hughes, Lecce, \& Wilson, 2007; Ornaghi \& Grazzani Gavazzi, 2009; Ruffman et al., 2002; Symons, 2004).

Fewer studies however have investigated the relationship between ToM and mental state language in school-age children, despite the fact that competence in both these areas continues to develop throughout the primary school years and beyond (Camaioni, Longobardi, \& Bellagamba, 1998; Fox, 1991; Lecce, Caputi, \& Pagnin, 2009; Longobardi, Pistorio, \& Renna, 2009; Pelletier, 2006). In this age range, ToM is also defined as ability to mentalize, that is to refer to mental states, explicitly label them and use them to explain behavior (Meins, Fernyhough, Johnson, \& Lidstone, 2006). During primary school education, language plays a role in promoting general cognitive development as well as more sophisticated mind reading abilities by means of literacy processes, conversation and 
metalinguistic activities including reflection on the psychological lexicon (Astington, 2000; Kamawar \& Olson, 2009). The capacity to use and reflect on mental-state language is a correlate of academic achievement during the childhood years (Olson, 1994; Pelletier, 2006) in which ability to pass both second-order false-belief tasks and emotion understanding tests has been found to improve significantly, particularly between the ages of 7-8 and 10-11 (Pons \& Harris, 2005; Pons, Harris, \& de Rosnay, 2004).

A careful analysis of the literature, as we shall see shortly, reveals that most of the research carried out on the topic to date has examined in childhood the use of mental-state language with relatively few studies focusing on the comprehension of such language.

The use of mental state language in children over the ages of 6-7 years has been evaluated by means of non-discursive or non-interactional tasks, such as analysis of their essay-writing. For example, Camaioni et al. (1998) conducted a study in which they asked third and fifth grade primary school children to complete one fictitious story and to invent another. The older children used a significantly higher number of cognitive terms and a significantly lower number of terms relating to perception and volition than the younger children; furthermore, in fifth grade the children used a richer cognitive lexicon including not only verbs such as know, think, remember but also more complex terms such as reflect, think up, be disconcerted. In addition, there were interesting gender differences: girls produced a greater variety of terms referring to inner states and positive emotions than did boys. However, this study did not examine the relationship between psychological lexicon and theory-of-mind development.

Children's use of internal-state language was also investigated by Meins et al. (2006). The authors used two tasks (book narration and describe-a-friend) to evaluate mental state talk, and the strange stories task to assess ToM, in a sample of 7-9-year-olds. They found that in this age range theoryof-mind performance was not related to children's use of psychological lexicon. These findings are similar to those reported by Charman and Shmueli-Goetz (1998) in a study with a sample of 6-8year old children whose use of internal state talk while narrating a wordless book was unrelated to measures of ToM.

Somewhat different results have emerged from two recent Italian studies. Lecce et al. (2009) explored third grade children's internal-state talk in relation to theory of mind, while controlling for language ability. They found that when the effects of individual differences in verbal ability were partialled, children's inner-state talk was still significantly correlated with performance on theoryof-mind tasks. In a study with children between 8 and 10.5 years of age, Ornaghi, Grazzani Gavazzi, and Zanetti (2010) also found some correlations between use of internal state talk, measured by a non-interactional task, and scores on ToM tasks.

With regard to the comprehension of mental-state language, early studies typically examined this variable in relation to age, academic performance and learning (e.g., Astington \& Olson, 1990). More recent work has begun to focus on the relationship between comprehension of mentalistic language and ToM development. Antonietti, Liverta Sempio, Marchetti, and Astington (2006) used a measure to evaluate understanding of internal-state language, specifically mental verbs such as remembering and knowing, in a study with preschool and primary school children (4, 6 , and 8 years old $)$. They found comprehension of mental language to correlate with understanding of both epistemic and emotional inner states; however, the correlation between mental language understanding and performance on second-order false-belief tasks was low, presumably because the latter are difficult for children in this age range.

In a study of theory of mind and metacognitive language in relation to reading skills, Pelletier (2006) found strong correlations between comprehension of language of mind and theory of mind, for both second grade and fourth grade children. Similarly, Ornaghi et al. (2010) in the study cited above found that metacognitive and metalinguistic competencies, including comprehension of mental states, predicted children's scores on second-order false-belief tasks.

In sum, the studies reported to date have yielded partly contradictory results which do not enable firm conclusions to be drawn with regard to the relationship between psychological lexicon and theory of mind in school-age children. Most of these studies have focused either solely on the use, or solely on the comprehension of, psychological lexicon, without always making a clear theoretical distinction between the two variables. For example, some authors review the results of prior research on the 
use of psychological lexicon before going on to report the adoption of measures of mental language comprehension in their own work.

Given this research background, we chose to concurrently examine the relative contributions of use and comprehension of mental-state language to variance in the ToM performance of primary school children. In addition, because mentalistic language includes both cognitive and emotional terms, we also set out to investigate the impact of use and comprehension of mental terms on emotional theory of mind (Harris, 1989).

\subsection{Aim and hypotheses}

The overall aim of this work was to explore the link between use and comprehension of mental state language on the one hand, and epistemic and emotional theory of mind on the other, in children between the ages of 8 and 11. More specifically, we wished to verify whether there were correlations between frequency of use and/or comprehension of psychological language, and performance on theory-of-mind tasks. We made no particular prediction about the association between use of mental-state talk and ToM, given that the findings reported in the literature to date are ambiguous and contradictory. In contrast, on the basis of previous studies we hypothesized that a significant correlation would be found between participants' performance on metacognitive language comprehension tests, and their scores on theory-of-mind tasks.

\section{Method}

\subsection{Participants}

Taking part in the study were 110 children ( 55 boys and 55 girls) of school age (mean age $=9$ years and 7 months; $S D=12.7$ months). Of these, 49 were third grade students (mean age $=8$ years and 6 months; $S D=3.1$ months) and 61 were fifth grade students (mean age $=10$ years and 6 months; $S D=4.4$ months). The children were pupils at two state primary schools located in predominantly middleclass urban districts of Northern Italy. Parental consent was obtained for all participants. The protocols of foreign children who had difficulty in producing and understanding Italian were excluded from the data analysis, as were those of children diagnosed with linguistic or cognitive deficits.

\subsection{Materials and procedure}

The participants completed, in counterbalanced order, six measures evaluating: verbal ability, epistemic and emotional theory of mind, understanding of metacognitive language, frequency and type of psychological lexicon used. The individual measures are described here below, followed by an outline of the data coding system. While the first five measures are conventional tests involving right or wrong answers, the sixth - aimed at evaluating the use of psychological lexicon - is a freestyle writing exercise.

Verbal ability. As nearly all of the tasks used in the study relied heavily on language production or comprehension, we included a measure of language ability for control purposes, administering the TAM-2 (Pinto, Candilera, \& Iliceto, 2003), a standardized linguistic test assessing children's receptive language and their knowledge of the rules of language usage. We used the following subtests: synonymity, comprehension, acceptability, and ambiguity. Participants were required to listen to one or more target sentences and to respond to a single question. For example, in the comprehension subtest, the target phrase is "The queen kissed the frog" and the corresponding question "Who was kissed?"

False belief battery. Participants were assessed on two second-order false belief tasks: the lookprediction task and the say-prediction task (Liverta Sempio, Marchetti, Castelli, Lecciso, \& Pezzotta, 2005). First-order false belief tasks require making inferences about someone's false belief about a matter of fact. They are typically passed by 4 -year-old kids. Second-order false belief tasks require making inferences about someone's false attribution of belief. These tasks are usually passed by children from 7 to 9 years old. In the look-prediction test, the child is asked to predict where the protagonist of a story thinks that another story character will look for an object; in the say-prediction test, the child 
is asked to predict what the protagonist thinks another character will say about a gift he or she is to receive for his or her birthday. The two illustrated stories are read to the participant who is then required to answer five questions: a memory control question (e.g., Did Mary see John hide the pack of cards under the bed?), a reality control question (e.g., Where does Mary think the pack of cards is?), a first-order false belief question (e.g., Does John know that Mary saw him hide the pack of cards under the bed?), a second-order false belief question (e.g., Where does John think that Mary will first look for the pack of cards when she comes back into the room?) and a justification question (e.g., Why does John think that Mary will search there?). Of these, the last two questions are those which specifically assess second-order false belief understanding.

Test of emotion comprehension (TEC). This test was devised by Pons and Harris (2000), and the current study used the standardized Italian version (Albanese \& Molina, 2008). The TEC is used to evaluate emotion understanding in children between the ages of 3 and 11 and is considered a measure of emotional theory of mind. Specifically, it tests understanding of the nature, causes and regulation of emotion broken down into nine components: recognition (capacity to recognize and name basic emotions), external causes (awareness that emotions may be caused by external circumstances, such as receiving a gift), desire (understanding of the role of desires in emotion), beliefs (awareness that individuals' beliefs, whether true or false, influence their emotional reactions), memories (awareness of the role of memories in emotional experience), regulation (awareness that emotion may be controlled and regulated by the use of specific strategies), distinguishing apparent and felt emotions (awareness that there may be a discrepancy between what an individual really feels and manifest emotion), mixed emotions (awareness that individuals may sometimes experience mixed emotions) and moral emotions (awareness of the role of moral precepts in determining emotional experience). Children are showed a series of cartoon scenarios placed at the top of each page of a book. The bottom part of each page shows four possible emotional outcomes depicted by facial expressions. The researcher reads a short story while the child looks at the scenario. The child is then asked to point to the facial expression that fits best with the story (her answer is typically non-verbal). Given the age of the participants and following the developmental model of emotion comprehension put forward by Pons et al. (2004), only the more complex components of the TEC were administered in this study, namely beliefs, regulation, concealment, mixed and moral emotions.

Test of metacognitive and metalinguistic verb comprehension (Antonietti, Liverta Sempio, \& Marchetti, 2006b). This test is a measure of metacognitive language comprehension. It is made up of a series of brief stories, each of which contains the generic verb 'think' or 'say'; for each target verb there are three stories based on the subject matter of history, mathematics and naive psychology respectively. The participant is required to appropriately substitute the generic verb in each story with a more specific metacognitive or metalinguistic verb. Each verb is chosen from amongst four options, only one of which is correct (the target verb). The following are the nine target verbs: five mental verbs, which may be used to substitute 'think' (deduce, doubt, hypothesize, presume and remember) and four metalinguistic verbs, which may be used to substitute 'say' (admit, conclude, confirm and foresee). Numerous authors (e.g., Astington \& Olson, 1990; Antonietti et al., 2006; Olson, 1994) maintain that all these verbs belong to the general category of mental state language, given that to understand their meaning children do not have to represent a content alone, but rather "a mind that is thinking", in other words a mental process.

Describe-a-friend task (Meins et al., 2006). This instrument is designed to assess both frequency and type of psychological lexicon used by participants in describing their best friend. We converted the original short interview developed by Meins et al. (2006) to a written narrative format. In order to encourage use of psychological language, we slightly modified the original questions to the following three prompts: (a) Please write down everything that comes to mind about your best friend; (b) In particular, describe your best friend's personality; (c) What do you like and what do you not like about him or her?

The measures were administered either collectively or individually. Specifically, the written description of best friend task and the metacognitive and metalinguistic verb comprehension test were administered to the entire class group on two different days; the test on verbal ability, the TEC and the two false-belief tasks were administered individually to each participant at one sitting. 


\subsection{Data coding}

Verbal ability. Performance on the TAM-2 was assessed by awarding a score of 1 to every correct answer and a score of 0 to every wrong answer, yielding a maximum possible score of 55 . Two independent judges coded the answers; inter-rater agreement, assessed using Cohen's Kappa, was satisfactory $(\kappa=.83)$.

Second-order false belief tasks. Performance on these tasks was assessed using the recommended right-wrong dichotomous scoring system, whereby correct answers are assigned a score of 1 and incorrect answers a score of 0 . With regard to the first three control/memory questions, if the participant fails to answer or provided a wrong answer, the researcher supplies the correct answer in order to ensure that the story has been fully understood. In this study, only one participant answered a memory question incorrectly on one of the two tasks and was excluded from the data analysis as a result. The answers to questions four and five are those which effectively assess second-order false belief understanding. Thus for the purposes of our study, scores were assigned only for these two questions, yielding total scores of $0-4$.

Test of emotion comprehension. Performance on the TEC was assessed by awarding a score of 1 to every correct answer and a score of 0 to every wrong answer. Of the five components of emotion understanding evaluated in our study (Beliefs, Regulation, Concealment, Mixed and Moral Emotions), four consist of a single item (minimum score 0 , maximum score 1 ) and one (the moral emotions component) consists of two items (minimum score 0 , maximum score 2). Summing the correct answers for all of the items administered, a total score ranging from 0 to 6 was obtained.

Test of metacognitive and metalinguistic verb comprehension. For this test too a score of 1 is awarded for each correct choice of target verb and a score of 0 for each inappropriate choice. Each of the nine target verbs is evaluated by three different stories. Thus participants could obtain scores ranging from a minimum of 0 to a maximum of 27.

Describe-a-friend task. Two types of coding were applied to the texts: one to obtain a measure of the length of the narrative and another to assess the frequency with which different types of mental state terms were used. The length of the texts was calculated by counting the total number of words used by each participant to answer the three questions.

Occurrences of mental state language were classified following a scheme adapted from Bartsch and Wellman (1995) and Meins et al. (2006) which included six internal state categories: perception, volition, ability, emotion (positive and negative), cognition, and morality. Only genuine psychological lexicon was coded, that is mental terms really denoting an understanding of mental states; thus, mere repetition of mental terms of the written format, or mental terms used conversationally (e.g., "You know, yesterday I went to see my grandparents") were excluded from the coding, as was repetition of terms used in the prompt questions (e.g., "like" in the third question). Finally, any terms repeated within the same answer were counted only once. The inter-rater reliability of this coding was satisfactory $(\kappa=.82)$.

In order to control for the effect of the huge variation in length on the use of psychological lexicon, the raw data was converted into percentage frequencies, calculated in relation to the total number of words used by the participants. In addition, the data was transformed into arcsine values to normalize the distribution.

\section{Results}

The results are presented in three sections covering general descriptive statistics and age comparison, correlations, and regression analyses. No significant differences were found as a function of gender in terms of performance on any of the administered measures.

\subsection{Descriptive statistics and age comparisons}

First, the mean scores obtained by the participants in the verbal task, in two false-belief tasks, the TEC and the test of metacognitive verb comprehension were calculated. The range of scores, means and standard deviations are reported in Table 1. 
Table 1

Means and standard deviations of total scores in the measures of competence.

\begin{tabular}{lcrr}
\hline Test & 8 years old group & 10 years old group & Whole sample \\
\hline Verbal ability & $40.80(4.60)$ & $44.98(6.02)$ & $43.08(5.79)$ \\
False-belief battery & $2.22(1.34)$ & $3.01(1.19)$ & $2.65(1.31)$ \\
Emotion comprehension & $3.61(1.25)$ & $4.44(1.04)$ & $4.07(1.21)$ \\
Metacognitive language comprehension & $8.84(2.08)$ & $12.72(2.78)$ & $10.97(3.15)$ \\
Use of psychological lexicon & $10.82(5.58)$ & $10.40(4.86)$ & $10.58(5.18)$ \\
\hline
\end{tabular}

Note: Standard deviations are provided in brackets.

With regard to the written description task, the mean length of the narratives was 62 words (range: $16-129 ; S D=27.8$ ). The mean number of occurrences of psychological lexicon was 6.06 (range: 1-13; $S D=2.96$ ). Sixty-four percent of the mental terms used were emotional terms, $14.7 \%$ were cognitive, $11.7 \%$ related to volition and ability, $9.4 \%$ to moral judgment, and only $0.2 \%$ to perception.

A series of ANOVAs were run to test for the relationship between age and performance on the various tasks as well as frequency and type of psychological lexicon produced. As shown in Table 1, the 10-year-olds obtained significantly higher mean scores than the 8-year-olds on the following measures: verbal ability $\left(F_{(1,107)}=16.0 ; p<.001\right.$; partial $\left.\eta^{2}=.131\right)$, false belief battery $\left(F_{(1,109)}=13.2\right.$; $p<.001$; partial $\left.\eta^{2}=.111\right)$ and TEC $\left(F_{(1,109)}=13.8 ; p<.001\right.$; partial $\left.\eta^{2}=.115\right)$, especially on the components regarding the role of morality in emotion $\left(F_{(1,109)}=9.9 ; p=.002\right.$; partial $\left.\eta^{2}=.086\right)$ and the potentially mixed nature of emotional experience $\left(F_{(1,109)}=9.78 ; p=.002\right.$; partial $\left.\eta^{2}=.084\right)$.

In order to compare use of psychological lexicon across the age groups, an ANOVA was carried out on the normalized data. We did not find significant differences between the two age groups in terms of overall frequency. The only statistically significant difference was in relation to the type of psychological lexicon used; specifically, the younger children tended to make more frequent use of moral judgment terms $F_{(1,109)}=6.22 ; p=.01$; partial $\eta^{2}=.056$ ).

\subsection{Relationship between psychological lexicon and theory of mind}

Correlational analyses were carried out to explore the relationship between use and understanding of psychological lexicon on the one hand and theory-of-mind development on the other.

As illustrated in Table 2, there were positive correlations between all variables. Whereas the correlations between use of psychological lexicon and ToM were at $<.0 .5$ level of statistical significance, the relations between comprehension of such language and theory of mind were higher (at $<.01$ level).

In addition, regression analyses were conducted to investigate the relationship between psychological lexicon and theory of mind in greater depth. Specifically, we wished to explore the respective impact of use and comprehension of metacognitive language in terms of explaining variance in epistemic and emotional theory of mind, when controlling for age and verbal ability. Four separate hierarchical linear regressions were run, using the enter method to add the independent variables step by step in the desired order, so as to obtain two full models for each of the dependent variables. In all models, the covariates age and verbal ability were entered first, at Step 1 . The two complementary

Table 2

Correlations between variables $(N=110)$.

\begin{tabular}{llllll}
\hline & 1 & 2 & 3 & 4 & 5 \\
\hline 1. Age & - & & & & \\
2. Verbal ability & $.328^{* *}$ & - & & & \\
3. False-belief battery & $.313^{* *}$ & $.246^{*}$ & - & & \\
4. Emotion comprehension & $.378^{* *}$ & $.266^{* *}$ & $.316^{* *}$ & - & - \\
5. Metacognitive language comprehension & $.621^{* *}$ & $.365^{* *}$ & $.428^{* *}$ & $.400^{* *}$ & $-306^{* *}$ \\
6. Use of psychological lexicon & $.293^{* *}$ & $.217^{*}$ & $.243^{*}$ & $.246^{*}$ & - \\
\hline
\end{tabular}

${ }^{*}<.05$ level (all significance tests are 2-tailed).

$* *<.01$ level (all significance tests are 2-tailed). 
Table 3

Hierarchical regression analysis: Model A.

\begin{tabular}{|c|c|c|c|c|c|c|}
\hline \multirow[t]{2}{*}{ Variable } & \multicolumn{3}{|c|}{ Epistemic ToM } & \multicolumn{3}{|c|}{ Emotional ToM } \\
\hline & $B$ & $S E B$ & $\beta$ & $B$ & $S E B$ & $\beta$ \\
\hline \multicolumn{7}{|l|}{ Step 1} \\
\hline Age & .025 & .010 & $.246^{*}$ & .032 & .009 & $.335^{* *}$ \\
\hline Verbal ability & .036 & .022 & .158 & .034 & .020 & .162 \\
\hline \multicolumn{7}{|l|}{ Step 2} \\
\hline Age & .005 & .012 & .046 & .020 & .011 & .210 \\
\hline Verbal ability & .021 & .022 & .091 & .025 & .020 & .120 \\
\hline Metacognitive language comprehension & .149 & .049 & $.357^{* *}$ & .087 & .045 & $.230^{*}$ \\
\hline \multicolumn{7}{|l|}{ Step 3} \\
\hline Age & .003 & .012 & .029 & .019 & .011 & .193 \\
\hline Verbal ability & .018 & .022 & .080 & .029 & .020 & .109 \\
\hline Metacognitive language comprehension & .140 & .049 & $.335^{* *}$ & .079 & .045 & $.224^{*}$ \\
\hline Use of psychological lexicon & .051 & .042 & .117 & .045 & .038 & .109 \\
\hline
\end{tabular}

regression models for each of the dependent variables were then continued as follows: in one model (A) metacognitive language comprehension was entered at Step 2 and use of psychological lexicon at Step 3 (Table 3), while in the other model (B) these two variables were entered in reverse order (Table 4). Regression assumptions were tested and found to be fulfilled. Multicollinearity was not present in the data, with Variance Inflation Factor (VIF) scores for all variables below the standard cut-off point.

\subsection{Testing the contribution of use and comprehension of mental state language to explain false belief understanding}

Model $A$. The variables age and verbal ability were entered together at Step $1\left(F_{(2,106)}=6.45, p=.002\right)$, yielding a multiple correlation coefficient of $.33\left(R^{2}=.093\right)$. Of the two covariates, only age was found to be a statistically significant indicator of the dependent variable $(\beta=.246 ; p=.013)$. At Step $2\left(F_{(3,106)}=7.797 ; p=<.001\right)$, on entering metacognitive language comprehension $(\beta=.357 ; p=.003)$, explained variance increased by $7 \%\left(R=.430 ; R^{2}=.161\right)$ while the beta coefficient for age decreased $(\beta=.046)$ and was no longer statistically significant. At Step $3\left(F_{(4,106)}=6.253 ; p<.001\right)$, the variable use of psychological lexicon was entered, yielding a negligible increase in the value of $R^{2}(R=.444$;

Table 4

Hierarchical regression analysis: Model B.

\begin{tabular}{|c|c|c|c|c|c|c|}
\hline \multirow[t]{2}{*}{ Variable } & \multicolumn{3}{|c|}{ Epistemic ToM } & \multicolumn{3}{|c|}{ Emotional ToM } \\
\hline & $B$ & $S E B$ & $\beta$ & $B$ & $S E B$ & $\beta$ \\
\hline \multicolumn{7}{|l|}{ Step 1} \\
\hline Age & .025 & .010 & $.246^{*}$ & .032 & .009 & $.335^{* *}$ \\
\hline Verbal ability & .036 & .022 & .158 & .034 & .020 & .162 \\
\hline \multicolumn{7}{|l|}{ Step 2} \\
\hline Age & .021 & .010 & $.205^{*}$ & .029 & .009 & $.301^{* *}$ \\
\hline Verbal ability & .031 & .022 & .136 & .030 & .020 & .143 \\
\hline Use of psychological lexicon & .070 & .043 & .159 & .055 & .038 & .135 \\
\hline \multicolumn{7}{|l|}{ Step 3} \\
\hline Age & .003 & .012 & .029 & .019 & .011 & .193 \\
\hline Verbal ability & .018 & .022 & .080 & .023 & .020 & .109 \\
\hline Use of psychological lexicon & .051 & .042 & .117 & .045 & .038 & .109 \\
\hline Metacognitive language comprehension & .140 & .049 & $.335^{* *}$ & .079 & .045 & $.224^{*}$ \\
\hline
\end{tabular}

${ }^{*} p<.05$ (all significance tests are 2-tailed).

${ }^{* *} p<.01$ (all significance tests are 2-tailed). 
$R^{2}=.165$ ) with metacognitive language comprehension remaining the only significant indicator of false belief understanding.

Model B. This second model was identical to Model A, but reversing the order of entry in Steps 2 and 3. Thus use of psychological lexicon was entered at Step $2\left(F_{(3,106)}=5.262 ; p=.002\right)$, yielding a $1 \%$ increase in explained variance $\left(R=.365 ; R^{2}=.108\right)$, while age continued to be a significant factor, although to a lesser extent than at Step 1 and with a barely statistically significant $p$ value $(\beta=.205$; $p=.042$ ). At Step 3, with the entry of metacognitive language comprehension, explained variance increased by $6 \%$. The beta coefficient for age was no longer significant, again leaving metacognitive language comprehension as sole significant predictor $(\beta=.335 ; p=.005)$.

In sum, taking the two models together we may conclude that, once age and verbal ability have been controlled for, the comprehension of metacognitive language is the factor that better explains the variance of children's false belief understanding.

\subsection{Testing the contribution of use and comprehension of mental state language to explain emotion understanding}

Model A. At Step $1\left(F_{(2,106)}=10.89 ; p<.001\right)$ the covariates age and verbal ability were entered $\left(R=.416 ; R^{2}=.157\right)$. Age was found to be a significant variable with a beta coefficient of $\beta=.335$ $(p=.001)$. At Step $2\left(F_{(3,106)}=8.743 ; p<.001\right)$, with the entry of metacognitive language comprehension ( $\beta=.230 ; p=.04)$ explained variance increased by $3 \%\left(R=.451 ; R^{2}=.180\right)$ while age no longer displayed significant explanatory power. At Step $3\left(F_{(4,106)}=6.919 ; p<.001\right)$, use of psychological lexicon was entered yielding a negligible increase in variance $\left(R=.462 ; R^{2}=.183\right)$.

Model $B$. The entry of use of psychological lexicon at Step 2 yielded an increase in explained variance of $1 \%\left(R=.435 ; R^{2}=.166\right)$ with age remaining significant $(\beta=.301 ; p=.002)$. With the addition of metacognitive language comprehension at Step 3, there was a $2 \%$ increase in explained variance $\left(R=.462 ; R^{2}=.183\right)$ while age no longer showed significant explanatory power. Again, the two complementary regression models showed that, when the effects of verbal ability and age were controlled for, metacognitive language comprehension was also the factor that better explains the variance of children's emotion understanding.

\section{Discussion}

Our general aim in carrying out this study was to extend the existing research on mental state language in pre-school kids by examining the mental-state lexicon of primary school children. More specifically, we wished to explore whether at this age there are still correlations between both use and understanding of psychological terms on the one hand, and development of epistemic and emotional ToM on the other. As far as we know, no previous studies have simultaneously investigated use and comprehension of mentalistic terms in middle childhood, focusing on both the emotional and cognitive mind-reading.

We obtained two main findings. First, in middle childhood there continues to be a significant correlation between use of psychological lexicon and performance on tests of epistemic and emotional theory of mind. Nevertheless, the correlation is moderate. Second, and more interesting, the comprehension of metacognitive language plays a key role in explaining children's performance on theory-of-mind tasks, whereas use does not. In other words in middle childhood, comprehension of psychological lexicon is the strongest correlate, and best indicator of, mind-reading. In addition, we found that children's performance on different tasks is function of age but not of gender.

There are abundant research findings supporting the argument that the lexical semantic component of psychological vocabulary may foster theory of mind in preschool children (Astington \& Baird, 2005; Hughes \& Dunn, 1997; Jenkins \& Astington, 1996). Studying children attending the primary school, we focused on a less developed area of enquiry.

Our findings, though partly different to those reported by Meins et al. (2006), who did not find correlations between use of psychological lexicon and ToM abilities, are not in contrast to them. In fact, the correlations that we found were low, especially if they are compared with those concerning comprehension of mental-state language and ToM. These results suggest that in the very period 
in which key academic learning takes place and is consolidated (between 8 and 10-11 years of age) the relationship between language and theory of mind changes. While at an earlier stage of development, children's theory-of-mind performance was predicted by their verbal ability but not vice versa (Astington, 2000), now performance on second-order ToM tasks deals with advanced ability to reflect on and comprehend the language of inner states; this ability is more metalinguistic and metacognitive than purely linguistic. During the school age period, children not only expand their use of mental state language but also acquire awareness of the meaning of such language which in turn fosters their learning in a range of academic domains (e.g., science, history, math).

Once children begin primary school education and gain literacy skills, they formally study language as well as use it; this enables them to master the meaning of mentalistic terms pertaining to academic learning, such as interpret, deduce, predict, and hypothesize. This kind of metacognitive language (Astington, 2000; Olson, 1994) is by nature more complex than that used in the pre-literacy stage of infancy and early childhood, which typically features verbs such as think, believe, remember, see. Children can make spontaneous use of simpler mental-state language in their everyday interactions without necessarily being fully aware of its meaning. In contrast, to use the mentalistic terms associated with formal learning, such as deduce or hypothesize, they need the ability to make logical connections between facts and events, to anticipate the possible outcomes of actions, and so on. In essence, saying 'I want that toy' is not the same thing as saying 'I hypothesize that water will freeze at this temperature'. In line with this argument, as mentioned above, correlational studies have showed that higher academic achievement is associated with high scores on metacognitive and metalinguistic tasks evaluating comprehension of complex mentalistic terms (e.g., Antonietti et al., 2006b).

Our study also allowed us to simultaneously evaluate a number of components of emotion comprehension using a single standardized tool based on a well-established developmental model. We found that higher scores for comprehension of metacognitive language also predict higher scores on measures of emotional theory of mind, or what Pons and colleagues have termed 'meta-emotion' (Pons, Harris, \& Doudin, 2002). The five components of emotion understanding assessed in this study, which included appreciation of the mixed nature of some emotional experiences and the understanding that there may be discrepancies between felt and manifest emotion, correspond to the third level of development in the hierarchical model of emotion understanding proposed by Pons et al. (2002). This is termed the 'metacognitive level' as it requires second-order metarepresentational abilities, which in our study are in fact predicted by metacognitive language comprehension.

We also found age to explain significant variation, and gender no variation at all, for all the measures under study. Specifically older children score significantly higher on the entire range of measures used, and this finding is in line with previous studies (e.g., Antonietti, Liverta Sempio, \& Marchetti, 2006a; Fusté-Herrmann, Silliman, Bahr, Fasnacht, \& Federico, 2006). We wish to mention in passing here leaving more in-depth discussion to another context - that some of the 8-year-old participants in our study still had difficulty with the second-order false belief tasks. The literature reports conflicting evidence about the age at which most children can perform these tasks successfully, with some studies indicating 6-7 years, as mentioned above, and others 8-9 years. Our results are in line with the latter studies and fuel the debate about how use of this type of instrument to evaluate ToM abilities may influence the results obtained (variations and simplified versions of the tasks have led to improved performance: Astington, 1998; Baron-Cohen, Leslie, \& Frith, 1985; Leslie \& Frith, 1988).

A significant effect of age was also found for the advanced components of the test of emotion comprehension selected for use in this study. This finding is in line with the hierarchical developmental model proposed by Pons and Harris (2005) according to which children only master the more complex components of emotion understanding at around 10 years of age.

There was also a significant effect of age with regard to the type of mental terms used, since 8-yearolds use more moral terms. However, their range of vocabulary for this category is very limited (good and polite are the most frequently used expressions) and seems to be used to refer to an external and behavioral dimension of morality, such as tease, be mean to and tell lies (see also Grazzani Gavazzi, Ornaghi, \& Antoniotti, 2011). In contrast, the 10-year-olds make less frequent use of moral terms but produce a wider variety of expressions of moral judgment; these terms are also more sophisticated and relate to the internal sphere, such as forgive, sincerity, responsible, obedient/disobedient, betray, 
altruistic. This result is backed by the further finding that 10 -year-olds outperform 8 -year-olds on the moral component of the TEC.

No gender effects were found for any of the measures administered. In contrast to our initial hypothesis, girls were not found to produce more emotional terms than boys. Moreover both boys and girls make very frequent use of emotional terms. This finding was unexpected and may be interpreted as the outcome of an effective stimulus, insofar as writing about the personality traits of their best friends may have led the boys too to activate a familiar emotional dimension and to access a correspondingly rich and sophisticated linguistic repertoire.

The results of this study have practical implications. The link found between mental language comprehension and cognitive development in school-age children suggests that it may be important to engage children in activities promoting metalinguistic reflection and awareness with this age group. Past research has provided ample evidence of the contribution of teachers' use of language of mind (e.g., Astington \& Pelletier, 1996); more recently educational science has focused on how teachers may promote reflection on mentalistic language in the classroom. Our own previous research has shown this type of intervention to be effective in enhancing the ToM abilities of infant school children who were stimulated to reflect on the psychological lexicon through specific 'language games' (Ornaghi, Brockmeier, \& Grazzani Gavazzi, 2011).

Although our results confirm the potential interest of investigating language and cognition in middle childhood, some limitations of the study must be acknowledged. These include the relatively small age range examined - a more comprehensive study would include children from all levels of primary school - and lack of data regarding the general academic performance of the participants. With regard to the latter aspect, the findings of the study would be even more encouraging if measures of academic achievement had been used and found to correlate with the other measures of ability administered. As far as we are aware, academic achievement measures have only been included to date in studies on the relationship between use of psychological lexicon and ToM (e.g. Lecce et al., 2009).

Despite these limitations, our findings support the conclusions of our own earlier work (e.g., Grazzani Gavazzi \& Ornaghi, 2011) highlighting the benefits of using socio-cultural tools (such as lexicon, discussion, language and meta-language games) to promote development of ToM in educational contexts. This is especially relevant given the status of theory of mind as a socio-cognitive and emotional capacity that continues to grow and develop throughout the primary school years and beyond.

\section{Acknowledgments}

This research was supported by a grant from F.A. - 2009 (University of Milano-Bicocca) to Ilaria Grazzani Gavazzi. We are very grateful to the head-teachers, teachers and pupils of the participating schools. We wish to thank Dr. Clare O'Sullivan for the English revision of the paper, Dr. Alessandro Pepe for his assistance with the statistical analysis and Prof. David R. Olson for his encouraging comments on a draft version of this article.

\section{References}

Albanese, O., \& Molina, P. (Eds.). (2008). Lo sviluppo della comprensione delle emozioni e la sua valutazione. La standardizzazione italiana del Test di Comprensione delle Emozioni (TEC) (The development of emotion comprehension. The Italian validation of TEC). Milano: Unicopli.

Antonietti, A., Liverta Sempio, O., \& Marchetti, A. (Eds.). (2006). Theory of mind and language in developmental contexts. New York: Springer.

Antonietti, A., Liverta Sempio, O., \& Marchetti, A. (2006). Verbi metacognitivi e metalinguistici. In P. Iannello, \& A. Antonietti (Eds.), Quaderni di Psicologia Cognitiva (pp. 89-100). Milano: Edizioni ISU.

Antonietti, A., Liverta Sempio, O., Marchetti, A., \& Astington, J. W. (2006). Mental language and understanding of epistemic and emotional mental states: Contextual aspects. In A. Antonietti, O. Liverta Sempio, \& A. Marchetti (Eds.), Theory of mind and language in developmental contexts (pp. 1-30). New York: Springer.

Astington, J. W. (1998). Theory of mind, Humpty Dumpty and the icebox. Human Development, 41, 30-39.

Astington, J. W. (2000). Language and metalanguage in children's understanding of mind. In J. W. Astington (Ed.), Minds in the making (pp. 267-284). Oxford: Blackwell.

Astington, J. W. (2001). The future of theory-of-mind research: Understanding motivational states, the role of language, and real-world consequences. Child Development, 72(3), 685-687. 
Astington, J. W., \& Baird, J. A. (Eds.). (2005). Why language matters for theory of mind. Oxford: Oxford University Press.

Astington, J. W., \& Olson, D. R. (1990). Metacognitive and metalinguistic language: Learning to talk about thought. Applied Psychology, An International Review, 39(1), 77-87.

Astington, J. W., \& Pelletier, J. (1996). The language of mind: Its role in teaching and learning. In D. R. Olson, \& N. Torrance (Eds.), Handbook of education and human development (pp. 593-619). Cambridge: Cambridge University Press.

Astington, J. W., \& Peskin, J. (2004). Meaning and use: Children's acquisition of the mental lexicon. In J. M. Lucariello, J. A. Hudson, R. Fivush, \& P. J. Bauer (Eds.), The development of the mediated mind: Socio-cultural context and cognitive development (pp. 59-78). Hillsdale, NJ: Erlbaum.

Baron-Cohen, S., Leslie, A., \& Frith, U. (1985). Does the autistic child have a theory of mind? Cognition, 21, 37-46.

Bartsch, K., \& Wellman, H. M. (1995). Children talk about the mind. New York: Oxford University Press.

Bretherton, I., \& Beeghly, M. (1982). Talking about internal states: The acquisition of an explicit theory of mind. Developmental Psychology, 18(6), 906-921.

Brown, J. R., Donelan-McCall, N., \& Dunn, J. (1996). Why talk about mental states? The significant of children's conversations with friends, siblings, and mothers. Child Development, 67, 836-849.

Brown, J. R., \& Dunn, J. (1991). "You can cry, mum": The social and developmental implications of talk about internal states. British Journal of Developmental Psychology, 9, 237-256.

Camaioni, L., Longobardi, E., \& Bellagamba, F. (1998). Evoluzione dei termini di stati mentali nelle storie di fantasia scritte da bambini in età prescolare. Età Evolutiva, 60, 20-29.

Charman, T., \& Shmueli-Goetz, Y. (1998). The relationship between theory of mind, language, and narrative discourse: An experimental study. Current Psychology of Cognition, 17, 245-271.

Dunn, J., Brown, J., \& Beardsall, L. (1991). Family talk about feeling states and children's later understanding of others' emotions. Developmental Psychology, 27, 448-455.

Fox, R. (1991). Developing awareness of mind reflected in children's narrative writing. British Journal of Developmental Psychology, 9, 281-298.

Fusté-Herrmann, B., Silliman, E. R., Bahr, R. H., Fasnacht, K. S., \& Federico, J. E. (2006). Mental state verb production in the oral narratives of English- and Spanish-speaking preadolescents: An exploratory study of lexical diversity and depth. Learning Disabilities Research and Practice, 21(1), 44-60.

Grazzani Gavazzi, I., \& Ornaghi, V. (2011). Emotional state talk and emotion understanding: A training study with preschool children. Journal of Child Language, 38, 1124-1139.

Grazzani Gavazzi, I., Ornaghi, V., \& Antoniotti, C. (2011). Children's and adolescents' narratives of guilt: Antecedents and mentalization. European Journal of Developmental Psychology, 8(3), 311-330.

Harris, P. L. (1989). Children and emotion: The development of psychological understanding. Oxford: Basic Blackwell.

Harris, P. L., de Rosnay, M., \& Pons, F. (2005). Language and children's understanding of mental states. Current Directions in Psychological Science, 14(2), 69-73.

Howard, A. A., Mayeux, L., \& Naigles, L. R. (2008). Conversational correlates of children's acquisition of mental verbs and a theory of mind. First Language, 28, 375-402.

Hughes, C. (Ed.). (2011). Social understanding and social lives. From toddlerhood through to the transition to school. London: Psychology Press.

Hughes, C., \& Dunn, J. (1997). “Pretend you didn't know”: Preschoolers' talk about mental states in pretend play. Cognitive Development, 12, 477-497.

Hughes, C., \& Dunn, J. (1998). Understanding mind and emotion: Longitudinal associations with mental-state talk between young friends. Developmental Psychology, 34, 1026-1037.

Hughes, C., Lecce, S., \& Wilson, A. (2007). "Do you know what I want?” Preschoolers' talk about desires, thoughts and feelings in their conversations with sibs and friends. Cognition \& Emotion, 21, 330-350.

Hughes, C., Marks, A., Ensor, R., \& Lecce, S. (2010). A longitudinal study of conflict and inner state talk in children's conversations with mothers and younger siblings. Social Development, 19(4), 822-837.

Jenkins, J. M., \& Astington, J. W. (1996). Cognitive factors and family structure associated with theory of mind development in young children. Developmental Psychology, 34, 1026-1037.

Jenkins, J. M., Turrell, S. L., Kogushi, Y., Lollis, S., \& Ross, H. S. (2003). A longitudinal investigation of the dynamics of mental state talk in families. Child Development, 74(3), 905-920.

Kamawar, D., \& Olson, D. R. (2009). Children's understanding of referentially opaque contexts: The role of metarepresentational and metalinguistic ability. Journal of Cognition and Development, 10(4), 285-305.

Lecce, S., Caputi, M., \& Pagnin, A. (2009). “I know what you mean”: A study of individual differences in children's internal state talk in relation to school competence. Journal of. Applied Psycholinguistics, IX(3), 83-98.

Leslie, A. M., \& Frith, U. (1988). Autistic children's understanding of seeing, knowing and believing. British Journal of Developmental Psychology, 6, 315-324.

Liverta Sempio, O., Marchetti, A., Castelli, I., Lecciso, F., \& Pezzotta, C. (2005). (Mentalizing and social competence. Understanding false belief in typical and atypical development) Mentalizzazione e competenza sociale. La comprensione della falsa credenza nello sviluppo normale e patologico. Milano: Franco Angeli.

Lohman, H., \& Tomasello, M. (2003). The role of language in the development of false belief understanding: A training study. Child Development, 74, 1130-1144.

Longobardi, E., Pistorio, B., \& Renna, M. (2009). Relation between mental state talk, theory of mind and empathy during school age. Poster presented at the XIV European Conference on Developmental Psychology. Vilnius, August 18-22.

Meins, E., Fernyhough, C., Johnson, F., \& Lidstone, J. (2006). Mind-mindedness in children: Individual differences in internal-state talk in middle childhood. British Journal of Developmental Psychology, 24, 181-196.

Milligan, K., Astington, J. W., \& Dack, L. A. (2007). Language and theory of mind: Meta-analysis of the relation between language ability and false-belief understanding. Child Development, 78(2), 622-646.

Moore, C., Bryant, D., \& Furrow, D. (1989). Mental terms and the development of certainty. Child Development, 7, $198-218$.

Nelson, K. (2005). Language pathways into the community of minds. In J. W. Astington, \& J. A. Baird (Eds.), Why language matters for theory of mind (pp. 26-49). Oxford: Oxford University Press. 
Olson, D. R. (1988). On the origins of beliefs and other intentional states in children. In J. W. Astington, P. L. Harris, \& D. R. Olson (Eds.), Developing theories of mind (pp. 414-426). New York: Cambridge University Press.

Olson, D. R. (1994). The world on paper. Cambridge: Cambridge University Press.

Ornaghi, V., Brockmeier, J., \& Grazzani Gavazzi, I. (2011). The role of language games in children's understanding of mental states: A training study. Journal of Cognition and Development, 12(2), 239-259.

Ornaghi, V., \& Grazzani Gavazzi, I. (2009). (Children's understanding of the mind: A linguistic laboratory with stories for preschool children) La comprensione della mente nei bambini. Un laboratorio linguistico con storie per la scuola dell'infanzia. Trento: Erickson.

Ornaghi, V., Grazzani Gavazzi, \& Zanetti, M. A. (2010). Lessico psicologico e teoria della mente: Uno studio con bambini di scuola primaria. Età evolutiva, 97, 54-71.

Pelletier, J. (2006). Relations among theory of mind, metacognitive language, reading skills and story comprehension in L1 and L2 learners. In A. Antonietti, O. Liverta Sempio, \& A. Marchetti (Eds.), Theory of mind and language in developmental contexts (pp. 77-92). New York: Springer.

Pinto, M. A., Candilera, G., \& Iliceto, P. (2003). Test TAM-2. Roma: Scione Editore.

Pons, F., \& Harris, P.L. (2000). TEC, test of emotion comprehension (Unpublished). Oxford: Oxford University.

Pons, F., \& Harris, P. L. (2005). Longitudinal change and longitudinal stability of individual differences in children's emotion understanding. Cognition E' Emotion, 19(8), 1158-1174.

Pons, F., Harris, P. L., \& de Rosnay, M. (2004). Emotion comprehension between 3 and 11 years: Developmental periods and hierarchical organization. European Journal of Developmental Psychology, 1(2), 127-152.

Pons, F., Harris, P. L., \& Doudin, P. A. (2002). Teaching emotion understanding. European Journal of Psychology of Education, 17(3), 293-304.

Ruffman, T., Slade, L., \& Crowe, E. (2002). The relation between children's and mothers' mental state language and theory-of-mind understanding. Child Development, 73(3), 734-751.

Ruffman, T., Slade, L., Rowlandson, K., Rumsey, C., \& Garnham, A. (2003). How language relates to belief, desire, and emotion understanding. Cognitive Development, 18, 139-158.

Scholnick, E. K., \& Hall, W. S. (1991). The language of thinking: Metacognitive and conditional words. In S. A. Gelman, \&J. P. Byrnes (Eds.), Perspectives on language and thought: Interrelations in development (pp. 397-439). New York: Cambridge University Press.

Slade, L., \& Ruffman, T. (2005). How language does (and does not) relate to theory-of-mind: A longitudinal study of syntax, semantics, working memory and false belief. British Journal of Developmental Psychology, 23, 117-141.

Symons, D. K. (2004). Mental state discourse, theory of mind, and the internalization of self-other understanding. Development Review, 24, 159-188.

Symons, D. K., Fossum, K., \& Collins, T. B. K. (2006). A longitudinal study of belief and desire state discourse during mother-child play and later false belief understanding. Social Development, 15, 676-691.

Taumoepeau, M., \& Ruffman, T. (2008). Stepping stones to others' minds: Maternal talk relates to child mental state language and emotion understanding at 15, 24, and 33 months. Child Development, 79(2), 284-302.

Wang, Q., Doan, S. N., \& Song, Q. (2010). Talking about internal states in mother-child reminiscing influences children's selfrepresentations: A cross-cultural study. Cognitive Development, 25(4), 380-393. 